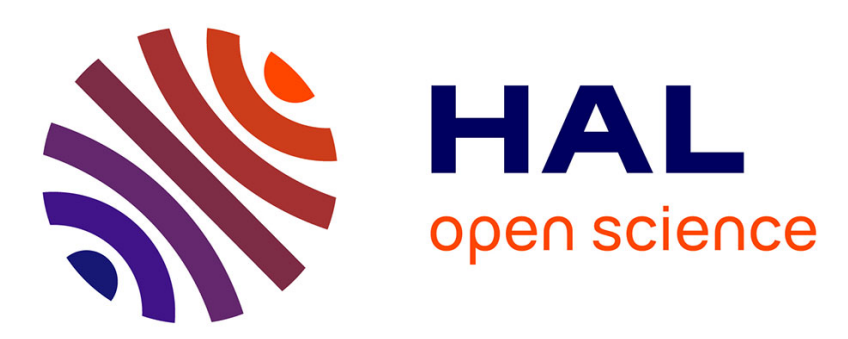

\title{
Microsurgical resection of a radicular hemangioblastoma with subarachnoid hemorrhage: how I do it
}

\author{
Constantin Tuleasca, Yohan Ducos, Philippe David, Nozar Aghakhani
}

\section{To cite this version:}

Constantin Tuleasca, Yohan Ducos, Philippe David, Nozar Aghakhani. Microsurgical resection of a radicular hemangioblastoma with subarachnoid hemorrhage: how I do it. Acta Neurochirurgica, inPress, 10.1007/s00701-020-04229-5 . hal-02449196

\section{HAL Id: hal-02449196 \\ https://hal.sorbonne-universite.fr/hal-02449196}

Submitted on 22 Jan 2020

HAL is a multi-disciplinary open access archive for the deposit and dissemination of scientific research documents, whether they are published or not. The documents may come from teaching and research institutions in France or abroad, or from public or private research centers.
L'archive ouverte pluridisciplinaire HAL, est destinée au dépôt et à la diffusion de documents scientifiques de niveau recherche, publiés ou non, émanant des établissements d'enseignement et de recherche français ou étrangers, des laboratoires publics ou privés. 


\title{
Microsurgical resection of a radicular hemangioblastoma with subarachnoid hemorrhage: how I do it
}

\author{
Constantin Tuleasca*, MD-PhD ${ }^{1,2,3,4,5}$, Yohan Ducos*, ${ }^{*} D^{1,2}$, Philippe David ${ }^{1}$, MD, Nozar \\ Aghakhani ${ }^{1}, \mathrm{MD}, \mathrm{PhD}$ \\ ${ }^{1}$ Assisstance Publique, Hôpitaux de Paris, Centre Hospitalier Universitaire Kremlin-Bicêtre, \\ Service de Neurochirurgie, Le Kremlin-Bicêtre, France \\ ${ }^{2}$ Sorbonne Université, Faculté de Médecine, Paris, France \\ ${ }^{3}$ Centre Hospitalier Universitaire Vaudois (CHUV), Neurosurgery Service and Gamma Knife \\ Center \\ ${ }^{4}$ Université de Lausanne (Unil), Faculté de Biologie et de Médecine (FBM) \\ ${ }^{5}$ Signal Processing Laboratory (LTS 5), Swiss Federal Institute of Technology (EPFL) \\ *Dr Tuleasca and Ducos equally contributed as a first author to the present manuscript
}

Conflict of interest: none

Key words: hemangioblastoma, subarachnoid hemorrhage, spine, tumor

\section{Corresponding author:}

Constantin Tuleasca, MD-PhD, Assistance Publique-Hôpitaux de Paris, Hôpitaux Universitaires ParisSud, Centre Hospitalier Universitaire Bicêtre, Service de Neurochirurgie, Paris, France; Sorbonne Université, Faculté de Médecine; Centre Hospitalier Universitaire Vaudois, Neurosurgery Service and Gamma Knife Center, Rue du Bugnon 44-46, BH-08, CH-1011, Lausanne, Switzerland; Tel: +41-21-314-26-02; Fax: +41-21-314-11-99;

e-mail: constantin.tuleasca@chuv.ch, constantin.tuleasca@gmail.com 


\section{Abstract}

\section{Background:}

Hemangioblastomas (HBL) are benign tumors occurring sporadically or associated with Von Hippel-Lindau syndrome (VHL):

\section{Method:}

We present the pre-, per- and postoperative course of a rare case with radicular HBL presenting with subarachnoid hemorrhage (SAH) in the frame of VHL. We describe the microsurgical approach.

\section{Conclusion:}

Complete microsurgical in bloc resection has been performed. Postoperative course was uneventful. 


\section{Introduction}

Hemangioblasoms (HBL) are highly vascularized tumors, which can be located in the central nervous system (CNS, frequently cerebellum and spinal cord)[6]. They are sources of significant morbidity and mortality throughout mass effect, with specific clinical manifestation depending on the anatomical location. Thirteen per cent of HBL can be found within the spinal canal[1].

It is extremely rare that spinal diseases cause spontaneous subarachnoid hemorrhage (SAH, $<1 \%$ of all non-traumatic cases)[2]. Moreover, SAH due to HBL is particularly infrequent, with only few reports described[3].

\section{Relevant surgical anatomy}

Hemangioblastomas are usually encapsulated and non-infiltrative tumors. In this context, total removal is feasible. However, one should pay attention to the violation of the tumor capsule, as this could potentially induce massive intraoperative bleeding[4].

The relevant surgical anatomy includes the spinal cord and the respective vascularization and spinal nerves, as well as the denticulate ligament. The former extends from the craniovertebral junction down to T12.

Care should be given to the origin of the artery of Adamkiewicz, to avoid the anterior spinal artery syndrome. This is the largest anterior segmental medullary artery. It typically arises from a left posterior intercostal artery, at the level of the $9^{\text {-th }}$ to $12^{\text {th }}$ intercostal artery, which branches from the aorta. It supplies the lower two-thirds of the spinal cord via the anterior spinal artery.

\section{Description of our technique}

Patient was installed in prone position. Fluoroscopy confirmed the level of the incision. No continuous intraoperative monitoring was performed. Kerison rongeurs performed laminectomy at the level of D11-L1.

Dura was classically opened on midline. Was observed significant vascular formation of the lateral aspect of the spinal cord, with numerous blood vessels entering to it, posterior to the dentate ligament.

We further proceeded to the opening of the arachnoid.

We continuously separated the nerve root from the tumor using microsurgical techniques at rostral and distal levels. Arterial feeders were coagulated with bipolar. The 
draining vein was preserved till the end to avoid tumor congestion. Moreover, the HBL has been detached by the coagulation of the remaining arterial feeders.

This was followed by the microdissection of the neural tissue away form the tumor. We further coagulated the vein, performed in bloc resection and sent the HBL to histological analysis.

\section{Indications}

In the case of sporadic tumors, surgery is indicated if new onsets of neurological deficit and/or tumor progression are encountered[4].

In the case of tumors in the frame of VHL, microsurgical resection is performed if neurological deficit related to one tumor/level or with tumor progression during follow-up is observed.

\section{Limitations}

The main limitations are related to radical resection, the origin of the artery of Adamkiewicz, nerve root preservation and spinal stability on long-term basis.

In this particular case, we had to gently mobilize the spinal cord. The dentate ligament was not readily seen and therefore could not permit better exposure for this lateral lesion.

\section{How to avoid complications}

Surgical resection must follow the strict rules that apply to AVM resection: coagulation of arterial feeders precedes the coagulation of the draining vein, which is preserved until the end of surgery.

Intraoperative neuromonitoring has been standardly accepted of clinical importance in microsurgical resection of intramedullary spinal cord lesions. Different modalities are used, including somatosensory evoked potentials, transcranial motor evoked potentials via limb muscles or spinal epidural space (D-waves), and dorsal column mapping. Although we don't routinely perform them in our center, we do believe that such adjunctive techniques can inform the surgeon intraoperatively. They can further lead to changes in the operative decision. Moreover, they can improve the postoperative neurologic functioning and outcome of such patients[7].

A quite recent intraoperative adjunct is near-infrared indocyanine green videoangiography in the microscopic resection of $\operatorname{HBLs}[5,9]$. This could provide real-time information about the tumor vasculature during surgery and help in intraoperative decision- 
making. One of the limitations is related to deep tumors, as well as those ventrally situated, with much limited benefits.

\section{Specific perioperative considerations}

\section{Preoperative workup}

A detailed preoperative neurological evaluation is compulsory.

Detailed MRI should be performed (figure 1).

\section{Instructions for the postoperative care}

Patients are frequently followed-up clinically and radiologically.

Care should be taken in the immediate postoperative period for eventual complications.

MRI at later and regular postoperative intervals are considered (figure 2).

In the frame of VHL, multidisciplinary management is mandatory.

\section{Specific information to give to the patient about surgery $\&$ potential risks}

The main inherent risks are the hemorrhagic one, as well as the eventual presence of a neurological deficit.

In the case of VHL recently discovered, one should consider a genetical testing $[8,10]$.

\section{Summary of 10 key points:}

1. Symptomatic patients with radicular HBL should be operated

2. In the case of tumors in the frame of VHL, microsurgical resection is performed if neurological deficit related to one tumor/level or with tumor progression during follow-up is observed.

3. A detailed preoperative neurological and neuroimaging evaluation is compulsory

4. Preoperative angiography for identifying the origin of the artery of Adamkiewicz is mandatory

5. Surgical resection must follow the strict rules that apply to AVM resection: coagulation of arterial feeders precedes the coagulation of the draining vein, which is preserved until the end of surgery.

6. Attention to the violation of the tumor capsule, as this could potentially induce massive intraoperative bleeding. 
7. Care should be taken in the immediate postoperative period for eventual complications.

8. The main inherent postoperative risks are the hemorrhagic one, as well as the eventual presence of a neurological deficit.

9. In the frame of VHL, multidisciplinary management is mandatory.

10. On long-term basis, spinal stability should be assessed

\section{Video legend:}

This video presents the case of a 64-years old male, diagnosed with Von Hippel-Lindau, and presenting with radicular hemangioblastoma with uncommon spinal and brain subarachnoid hemorrhage. After microsurgical resection, no postoperative deficit was encountered. Moreover, the patient fully recovered from preoperative paraparesis.

\section{Figure legends}

Figure 1: preoperative MRI related to our patient in the illustrative video

Figure 2: postoperative MRI assessment

\section{Compliance with Ethical Standards:}

Funding: This study was funded by Paris (CHU de Bicêtre) and Lausanne University Hospitals.

Conflict of Interest: The authors report no conflict of interest.

Ethical approval: All procedures performed in studies involving human participants were in accordance with the ethical standards of the institutional and/or national research committee and with the 1964 Helsinki declaration and its later amendments or comparable ethical standards.

Ethical approval: This article does not contain any research studies with human participants or animals performed by any of the authors. It represents a video of a surgical case. Patient gave approval for this publication. 


\section{References}

1. Browne TR, Adams RD, Roberson GH (1976) Hemangioblastoma of the spinal cord. Review and report of five cases. Archives of neurology 33:435-441

2. Cerejo A, Vaz R, Feyo PB, Cruz C (1990) Spinal cord hemangioblastoma with subarachnoid hemorrhage. Neurosurgery 27:991-993

3. Dijindjian M, Djindjian R, Houdart R, Hurth M (1978) Subarachnoid hemorrhage due to intraspinal tumors. Surgical neurology 9:223-229

4. Giammattei L, Messerer M, Aghakhani N, David P, Herbrecht A, Richard S, Parker F (2016) Surgical resection of medulla oblongata hemangioblastomas: outcome and complications. Acta neurochirurgica 158:1333-1341

5. Hao S, Li D, Ma G, Yang J, Wang G (2013) Application of intraoperative indocyanine green videoangiography for resection of spinal cord hemangioblastoma: advantages and limitations. Journal of clinical neuroscience : official journal of the Neurosurgical Society of Australasia 20:1269-1275

6. Joaquim AF, Ghizoni E, dos Santos MJ, Valadares MG, da Silva FS, Tedeschi H (2015) Intramedullary hemangioblastomas: surgical results in 16 patients.

Neurosurgical focus 39:E18

7. Kothbauer K, Deletis V, Epstein FJ (1997) Intraoperative spinal cord monitoring for intramedullary surgery: an essential adjunct. Pediatric neurosurgery 26:247-254 8. Lonser RR, Butman JA, Huntoon K, Asthagiri AR, Wu T, Bakhtian KD, Chew EY, Zhuang Z, Linehan WM, Oldfield EH (2014) Prospective natural history study of central nervous system hemangioblastomas in von Hippel-Lindau disease. Journal of neurosurgery 120:1055-1062

9. Tamura Y, Hirota Y, Miyata S, Yamada Y, Tucker A, Kuroiwa T (2012) The use of intraoperative near-infrared indocyanine green videoangiography in the microscopic resection of hemangioblastomas. Acta neurochirurgica 154:1407-1412; discussion 1412 10. Wanebo JE, Lonser RR, Glenn GM, Oldfield EH (2003) The natural history of hemangioblastomas of the central nervous system in patients with von Hippel-Lindau disease. Journal of neurosurgery 98:82-94 